\title{
ALTERAÇÕES DO ESMALTE DENTÁRIO EM CRIANÇAS NA PRIMEIRA INFÂNCIA
}

\author{
Patrícia Martines do Nascimento, Mirely Altero Gasparelli, Karine Takahashi \\ Universidade do Oeste Paulista - UNOESTE, Curso de Odontologia, Presidente Prudente, SP. e-mail: \\ karine@unoeste.br
}

\section{RESUMO}

O esmalte dental é um derivado ectodérmico produzido pelos ameloblastos, que se diferenciam das células do epitélio interno do órgão do esmalte. Qualquer fator sistêmico, local ou genético que possa afetar os ameloblastos, pode causar defeitos na superfície do esmalte dental. Este estudo tem por objetivo verificar a prevalência de defeitos hipoplásicos do esmalte dentário em crianças na primeira infância. Desse modo, os conhecimentos dos riscos aumentados de problemas na dentição em crianças na primeira infância nos permitirão utilizar medidas preventivas mais adequadas. Foram avaliadas 35 crianças de 6 a 72 meses, gêneros masculino e feminino, atendidas na Pediatria do Hospital Regional e na Maternidade do Hospital Regional. Após estabelecimento da dentição decídua, as crianças foram avaliadas clinicamente quanto à presença ou ausência de defeitos hipoplásicos no esmalte dentário. A prevalência de defeitos de esmalte (PDE) em crianças avaliadas foi de $8,6 \%$ (três crianças afetadas). Feminino foi de $48,6 \%$ e $51,4 \%$ para o sexo masculino. As crianças afetadas, $2(5,7 \%)$ tiveram defeitos de esmalte do tipo hipoplasia do esmalte e 1 (2,9\%) apresentaram defeitos tipo opacidade demarcada. Não foram encontradas crianças com defeitos tipo opacidade difusa. Em todas as crianças afetadas os dentes envolvidos eram os incisivos centrais superiores. Conclui-se que as alterações do esmalte dentário (hipoplasia e opacidades) acometem principalmente crianças que apresentam distúrbios neurológicos e/ou nutricionais ou complicações perinatais, sendo assim, crianças que não apresentam tais alterações, demonstram níveis de normalidade em relação aos tecidos dentários. Palavras-chave: Amelogênese, Dente Decíduo, Hipoplasia do Esmalte Dentário, Odontopediatria. Nutrição da criança.

\section{CHANGES OF TOOTH ENAMEL IN EARLY CHILDHOOD}

\section{ABSTRACT}

Tooth enamel is an ectodermal derivative produced by ameloblasts that differentiate the cells lining the inner enamel organic. Systemic, local or genetic factors that affect the ameloblasts may cause defects in the enamel surface. This study aims to determine the prevalence of hypoplastic defects of enamel in children in early childhood. Adding, improve knowledge of the increased risks of teeth problems in early childhood will allow us to use more suitable preventive procedures. We evaluated 35 children 6-72 months old, male and female, attending the Pediatric Regional Hospital, and Children's Regional Maternity Hospital. After establishment of the primary dentition, the children were evaluated clinically as the presence or absence of hypoplastic defects in tooth enamel. The prevalence of defects of enamel (PDE) in children evaluated was 8,6\% (3 affected children). Female was $48,6 \%$ and $51,4 \%$ for male. Affected children, $2(5,7 \%)$ had enamel defects of type enamel hypoplasia and 1 (2,9\%) had type defects demarcated opacity. We have not found children with type defects diffuse opacity. In all children affected teeth involved were the maxillary central incisors. We concluded that changes in the enamel (hypoplasia and opacities) mainly affects children who have neurological, nutritional and/or perinatal complications. So children who do not exhibit such changes, show normal levels in relation to dental tissues.

Keywords: Amelogenesis, Deciduous Teeth, Dental Enamel hypoplasia, Pediatric Dentistry, Child Nutrition. 


\section{INTRODUÇÃO}

O esmalte dental é um derivado ectodérmico produzido pelos ameloblastos, que se diferenciam das células do epitélio interno do órgão do esmalte. Estas células possuem grandes demandas energéticas devido à sua intensa atividade de síntese protéica e grande sensibilidade decorrente do fato de não estarem diretamente ligados a fontes de nutrientes e vasos sangüíneos. Qualquer fator sistêmico, local ou genético que possa afetar os ameloblastos, que são células extremamente sensíveis nestas fases, pode causar defeitos na superfície do esmalte dental ${ }^{1,2,3}$.

Sabe-se que é dividida em três estágios a formação do esmalte dentário: (I) o estágio da formação da matriz, onde as proteínas envolvidas na amelogênese são produzidas; (II) o estágio da calcificação, no qual é depositado mineral, e a maior parte das proteínas originais são removidas; e (III) o estágio da maturação no qual o esmalte recém mineralizado passa pelo processo final de calcificação, e as proteínas ainda remanescentes são removidas. Esses processos acontecem sob mudanças ambientais e influência genética, sendo assim, o desenvolvimento de defeitos de esmalte pode resultar de qualquer dano ocorrido nesses estágios. Observa - se o envolvimento de fatores sistêmicos e locais na patogênese desses defeitos de desenvolvimento. Dentre os distúrbios sistêmicos, citam-se os nascimentos traumáticos, infecções, desordens nutricionais, doenças metabólicas e medicamentos; dentre os fatores locais, o uso de laringoscópio e intubação endotraqueal, prolongada ventilação mecânica e nutrição por sonda oral, fraturas mandibulares, trauma cirúrgico, reparo de fendas lábio-palatinas, irradiação e infecções locais ${ }^{4,5,6}$.

Os defeitos do esmalte causados por injúrias aos ameloblastos apresentam-se clinicamente como quebras na continuidade do esmalte em forma de manchas, relevos ou outros distúrbios, que podem ser classificados em: hipoplasias e opacidades ${ }^{7}$.

A hipoplasia do esmalte é a formação insuficiente da matriz orgânica do esmalte dos dentes, resultante de lesão de suas células formadoras, os ameloblastos. De acordo com a intensidade e a extensão da agressão, podem surgir lesões discretas do ponto de vista clínico, sob a forma de um ou vários sulcos estreitos na superfície do esmalte ou lesões graves, com o aspecto de depressões profundas, dispostas horizontalmente ao redor do dente e atinge preferencialmente os elementos da região anterior da maxila. Já as opacidades são mais frequentes em primeiros molares. A hipoplasia de esmalte pode ser decorrente de causas sistêmicas, genéticas ou 
ambientais, que interferem na formação da matriz do esmalte e na sua posterior calcificação e maturação. Os fatores etiológicos correlacionados a hipoplasia são: prematuridade, baixo peso ao nascimento, deficiências nutricionais (vitamínicas A, C, D, cálcio, fósforo e fosfato), lesões cerebrais e defeitos neurológicos, síndrome nefrótica, alergias, problemas respiratórios, trauma durante 0 nascimento, febres exantematosas, rubéola, envenenamento pediátrico crônico por chumbo, fenda labial e palatina, sífilis congênita, radiação excessiva, fluorose, infecções, ou traumatismos locais, doenças da infância e antibióticos. A hipoplasia de origem sistêmica é denominada hipoplasia cronológica, uma vez que o defeito é encontrado em áreas do dente nas quais o esmalte estava em formação quando ocorreu a perturbação sistêmica ${ }^{8-17}$.

As opacidades foram diagnosticadas como mudanças na translucidez do esmalte, apresentando-se como áreas brancas, amarelas, ou marrons sem quebra na continuidade de superfície ${ }^{7,17,18}$.

Em um estudo, foram avaliados 15 pacientes nascidos prematuramente com peso médio de 852 gramas. A idade média das crianças era de 3 anos e 7 meses, e no exame clínico registrou-se a presença de hipoplasia e opacidade de acordo com os critérios da Federation Dentaire Internationale. Todas as crianças apresentavam defeitos de esmalte, sendo que em 3 observou-se a presença apenas de opacidade, principalmente nos primeiros molares e caninos inferiores, e nas outras 12 observou-se hipoplasia em pelo menos um dente, sendo os incisivos centrais e laterais superiores os mais afetados, seguidos pelos caninos superiores e inferiores. Assim, os autores puderam concluir que distúrbios severos no metabolismo de cálcio no período neonatal podem acarretar o desenvolvimento de defeitos no esmalte de dentes decíduos ${ }^{7}$.

A nutrição está relacionada com as células responsáveis pela formação do tecido dentário, da saliva e do epitélio oral. Distúrbios nutricionais que podem ocorrer no período de formação do feto, bem como no balanço energético-protéico, afetam a formação do tecido dentário. As alterações nutricionais, principalmente relacionadas à síntese protéica ou à mineralização, podem culminar em alterações estruturais dos tecidos dentários, bem como da forma, da posição e do tempo de erupção. A desnutrição retarda a cronologia de erupção dentária, o que implica dizer que crianças desnutridas têm seus dentes expostos ao meio bucal mais tardiamente ${ }^{5,20,21}$.

O exato mecanismo causador dos defeitos do esmalte dentário ainda constitui uma incógnita na literatura, porém, sugerese que a suplementação de cálcio e fósforo 
insuficiente possa aumentar o risco ao seu desenvolvimento ${ }^{17}$.

Complicações gestacionais, no momento do parto, ou nos primeiros 30 dias após o mesmo, podem levar a uma maior predisposição ao desenvolvimento dos defeitos no esmalte dentário ${ }^{10}$.

Defeitos do desenvolvimento do esmalte dentário apresentam grande importância clínica, uma vez que são responsáveis por problemas estéticos, sensibilidade dentária, anomalias dentofaciais e uma maior predisposição a cárie dentária ${ }^{11,22}$.

Desta forma, é importante que não somente os profissionais de Odontologia, mas os responsáveis pelas crianças tenham conhecimento sobre estas alterações que podem ocorrer na dentição decídua. Assim, haverá um maior índice de sucesso no diagnóstico, tratamento e prognóstico destas alterações.

Devido à grande variedade de afirmações encontradas na Literatura o objetivo deste trabalho é verificar a prevalência de defeitos hipoplásicos do esmalte dentário em crianças, atendidas no Hospital Regional da cidade de Presidente Prudente - SP, tanto na pediatria, quanto na maternidade. Desse modo, os conhecimentos dos riscos aumentados de problemas na dentição em crianças na primeira infância nos permitirão utilizar medidas preventivas mais adequadas.

\section{MATERIAIS E MÉTODOS}

Todos os procedimentos descritos foram aprovados previamente pela Comissão de Ética em Pesquisa (protocolo 1087/2012) da UNOESTE, e os responsáveis pelos pacientes foram esclarecidos e assinaram o Termo de Consentimento Livre e Esclarecido.

Foi realizada uma pesquisa sistematizada em bases de dados, sobre as alterações do esmalte dentário em crianças na primeira infância. Os dados obtidos foram tabulados e submetidos à análise estatística usando o teste Qui-Quadrado com nível de significância de 5\% (Bioestat - Belém, Pará, Brasil).

\subsection{Amostra}

Foram avaliadas 35 crianças de 6 a 72 meses, gêneros masculino e feminino, atendidas na Pediatria e na Maternidade de um hospital do interior do estado de São Paulo. A dentição decídua das crianças foi avaliada clinicamente quanto à presença ou ausência de defeitos hipoplásicos no esmalte dentário. As informações foram coletadas em fichas clínicas.

2.2 Critérios clínicos para anotação em ficha Foram avaliados clinicamente todos os dentes presentes da dentição decídua, 
classificando as alterações hipoplásicas em opacidades (manchas esbranquiçadas, irregulares, rugosas) e hipoplasia (perda de estrutura do esmalte).

Segundo a Federation Dentaire Internationale (FDI), a maior parte dos defeitos de esmalte nos dentes do ser humano podem ser classificados, segundo o seu aspecto macroscópico, em três tipos:
- Opacidade demarcada;

- Opacidade difusa;

- Hipoplasia.

O Quadro 1 demonstra dados da avaliação e comparação da dentição decídua dos voluntários.

Quadro 1. Cronologia de desenvolvimento da dentição decídua do arco superior.

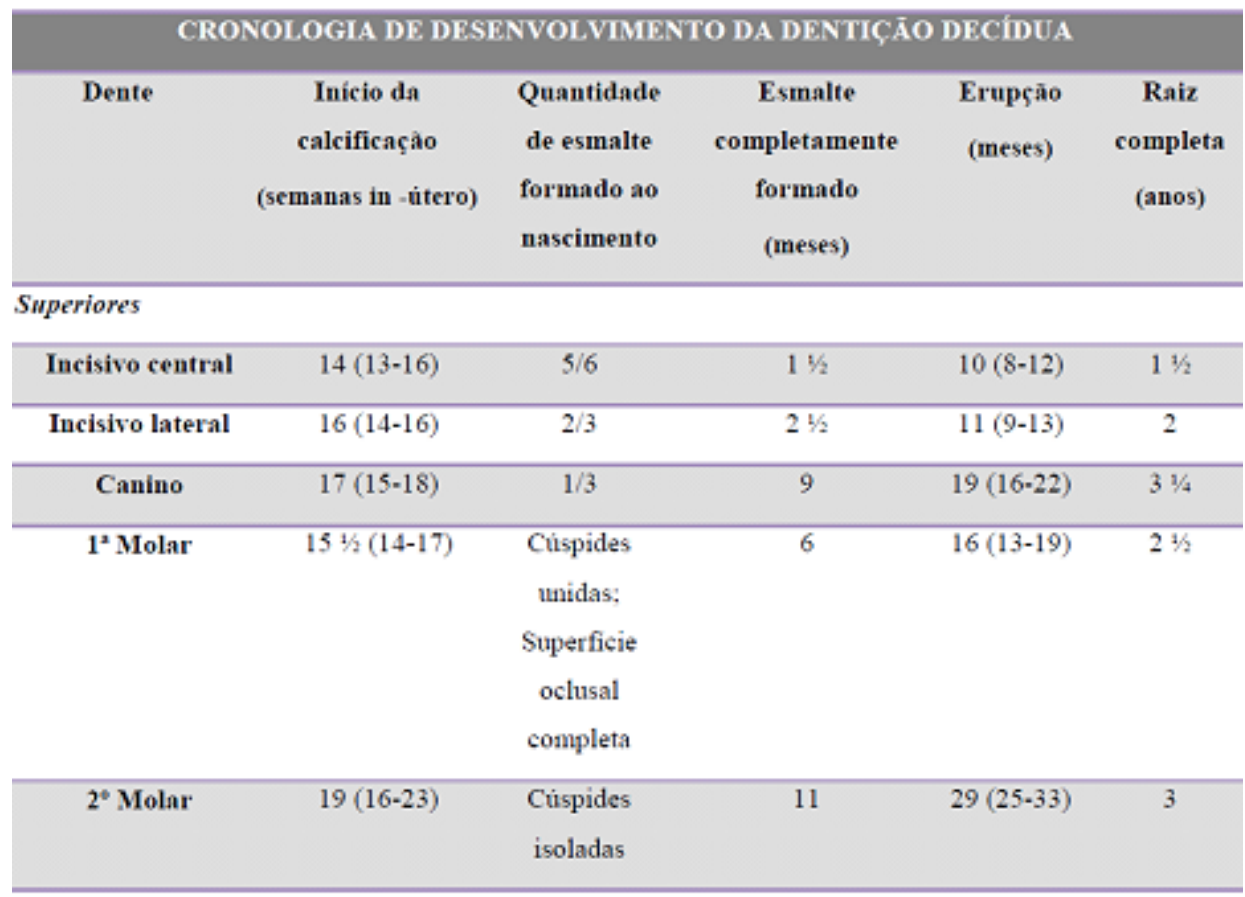

As alterações ainda foram classificadas quanto ao tipo, coloração, extensão e face em que se encontram.

Além disso, foi aplicado um questionário a mãe, relacionados a dados de anamnese da criança, verificando a ocorrência de problemas pré, peri e pós natais.
Os dados levantados foram anotados em ficha clínica para análise. Os pacientes que apresentaram defeitos de esmalte foram encaminhados para tratamento odontológico e preventivo na clínica de odontopediatria.

\section{RESULTADOS}

Não houve recusas a participar desta pesquisa e todos os envolvidos foram 
esclarecidos e assinaram o termo de consentimento livre e esclarecido.

Foram avaliados nesta pesquisa 35 voluntários: $18(51,4 \%)$ do gênero masculino e 17 (48,6\%) do feminino, com faixa etária de 6 a 72 meses (3,4 $\pm 2,5$ meses). Quando avaliado a presença de lesões na superfície do esmalte dentário dos dentes erupcionados, foi verificado a presença de alterações na superfície do esmalte sendo que 3 voluntários (8,6\%) apresentaram lesões, sendo que apenas 1 (2,9\%) apresentou opacidade do esmalte e $2(5,7 \%)$ apresentaram hiperplasia do esmalte (Figura $1)$.

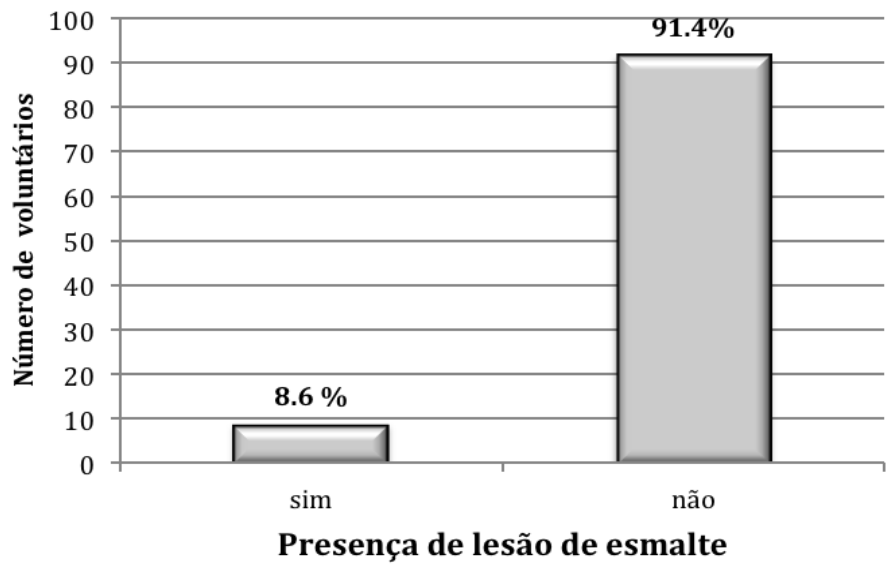

Figura 1. Dados obtidos expressos em frequência do número de voluntários avaliados que apresentaram alteração na superfície do esmalte $(n=35)$.

Dentre os $3(8,6 \%)$ voluntários que apresentaram a presença de alterações na superfície do esmalte, 2 (67\%) relataram história de parto prematuro.

Foram examinadas dentições decíduas de 35 crianças frequentadoras de um hospital do interior do estado de São Paulo. A prevalência de defeitos de esmalte dentário (DDE) nas crianças avaliadas foi de 8,6\% (3 crianças afetadas). Das 35 crianças avaliadas $48,6 \%$ eram do sexo feminino, e $51,4 \%$ do sexo masculino. Das crianças afetadas, 2 (5,7\%) apresentavam defeitos do esmalte do tipo hipoplasia do esmalte dentário e 1 (2,9\%) apresentava defeitos do tipo opacidade demarcada. Não foram encontradas crianças com defeitos do tipo opacidade difusa. Em todas as crianças afetadas os dentes envolvidos eram os incisivos centrais superiores (Tabela 1).

Tabela 1. Dados obtidos expressos em frequência dos dados clínicos obtidos pelos pais sobre eventos relacionados ao histórico médico dos voluntários $(n=34)$ : 


\begin{tabular}{lcc}
\hline \multirow{2}{*}{ Histórico dos voluntários } & \multicolumn{2}{c}{ Frequências } \\
\cline { 2 - 3 } & Sim & Não \\
\hline Peso abaixo do recomendado & $6(17 \%)^{\mathrm{a}}$ & $29(83 \%)^{\mathrm{a}}$ \\
\hline Prematuridade do parto & $9(26 \%)^{\mathrm{a}}$ & $26(74 \%)^{\mathrm{a}}$ \\
\hline Problemas pré natal & $2(6 \%)^{\mathrm{a}}$ & $33(94 \%)^{\mathrm{b}}$ \\
\hline Deficiência nutricional & $4(11 \%)^{\mathrm{a}}$ & $31(89 \%)^{\mathrm{a}}$ \\
\hline Intubação & $4(11 \%)^{\mathrm{a}}$ & $31(89 \%)^{\mathrm{a}}$ \\
\hline Nascimento cianótico & $2(6 \%)^{\mathrm{a}}$ & $33(94 \%)^{\mathrm{a}}$ \\
\hline Relato de uso de fórceps no nascimento & $0(0 \%)^{\mathrm{a}}$ & $35(100 \%)^{\mathrm{b}}$ \\
\hline Histórico de incubação & $5(14 \%)^{\mathrm{a}}$ & $30(86 \%)^{\mathrm{a}}$
\end{tabular}

Letras minúsculas comparadas em linha representam diferença estatisticamente significante entre os voluntários com e sem diagnóstico de transtorno hipercinético (Qui-Quadrado; $p<0,05$ ).

\section{DISCUSSÃO}

Neste trabalho, encontramos uma prevalência de $8,6 \%$ de defeitos de esmalte dentário na dentição decídua, o que foi similar a outros estudos encontrados na literatura, principalmente em população brasileira. Hoffmann et al. ${ }^{4}$ avaliaram 624 crianças aos 5 anos de idade e encontraram prevalência de $8,7 \%$ na dentição decídua. 0 que segundo, os mesmos autores, também corroboram com estudos realizados em lowa (EUA) que encontraram prevalência de $6 \%{ }^{15}$. Machado et al. $^{18}$ avaliaram crianças na dentição decídua e permanente na cidade de Presidente Prudente - SP e encontraram prevalência de aproximadamente $16 \%$. Porém, estes resultados foram menores quando comparados a outros trabalhos encontrados na literatura, Possobon et al. ${ }^{9}$ avaliaram 199 crianças onde 31 (15,57\%) apresentaram hipoplasia, Gomes ${ }^{10}$ avaliou 109 crianças com idades compreendidas entre os 6 e 9 anos de idade onde pelo menos um defeito de esmalte foi encontrado em $36,7 \%$ das crianças e a quantidade de opacidades encontrada foi similar sendo que $23,9 \%$ das crianças apresentaram opacidades demarcadas e $19,3 \%$ apresentaram opacidades difusas. Lunardelli e Peres ${ }^{11}$ avaliaram 2484 crianças de 3 a 5 anos de idade e encontraram prevalência de $24,4 \%$, segundo os autores a prevalência na literatura tende a ter grande variabilidade, o que pode ocorrer devido a características particulares da população estudada e aspectos metodológicos adotados, como variabilidade de índices a serem adotados e critérios de exame. 
Seow et al. ${ }^{7}$ afirma em seu estudo sobre diagnóstico clínico de defeitos hipoplásicos que alguns tipos de defeitos na dentição decídua podem ser detectados mais dificilmente do que na dentição permanente por causa de sua presença ser mais sutil. Além disso, a aparência mais esbranquiçada do esmalte decíduo pode dificultar o discernimento de lesões mais suaves.

Outro fator que merece destaque em nosso estudo é o fato de que todas as crianças afetadas apresentam problemas sistêmicos graves, com comprometimento neurológico e nutricional. Duas crianças apresentam hidrocefalia e outra apresenta anóxia cerebral. Gomes ${ }^{10}$ cita que complicações gestacionais, no momento do parto, ou logo após o seu acontecimento podem levar a defeitos de esmalte. Possobon et al. $^{9}$ afirmam que o trabalho de parto demorado, asfixia neonatal e condições sistêmicas graves podem acarretar em defeitos do desenvolvimento esmalte dentário.

Os distúrbios sistêmicos ocorridos logo após o nascimento da criança parecem atuar no mecanismo de armazenamento Áreas hipoplásicas apresentam menor mineralização do esmalte dentário, o que resulta em superfícies irregulares que permitem um maior acúmulo de biofilme e uma maior sensibilidade dentária. Desta forma, pode haver desenvolvimento de mineral e que posteriormente afeta os tecidos dentários ${ }^{10}$. Além disso, Diniz et al. ${ }^{17}$ estabelecem relação dos defeitos com metabolismo de cálcio deficiente nos pacientes afetados.

A função das células ameloblásticas é alterada pela privação de oxigênio, principalmente problemas respiratórios ao nascimento, o que acarretaria em alterações no processo de mineralização do esmalte dentário $^{10,16}$.

Os dentes mais afetados foram os incisivos superiores, o que corrobora com a grande maioria dos trabalhos encontrados na literatura. Possobon et al. $^{9}$ afirma que influências sistêmicas são freqüentes nos primeiros anos de vida e portanto os dentes geralmente mais afetados são incisivos e caninos, que tem sua calcificação correspondente a este período.

Os dentes decíduos têm um longo período pré e pós-natal de desenvolvimento. A formação da matriz e posterior calcificação inicia-se por volta da 14a semana de vida intra-uterina e continua por vários meses após o nascimento ${ }^{10}$.

lesões cariosas nos dentes afetados. Medidas preventivas e acompanhamento clínico são necessários, exigindo maior atenção dos profissionais. Em nosso estudo, os pacientes que apresentaram defeitos hipoplásicos de esmalte foram encaminhados para 
atendimento clínico e monitoramento na Clínica de Odontopediatria da Faculdade de Odontologia de Presidente Prudente.

\section{CONCLUSÃO}

Diante das afirmações encontradas neste estudo, pode-se concluir que as alterações do esmalte dentário (hipoplasia e opacidades) acometem principalmente crianças que apresentam distúrbios neurológicos e/ou nutricionais ou complicações perinatais, sendo assim, crianças que não apresentam tais alterações, demonstram níveis de normalidade em relação aos tecidos dentários.

\section{REFERÊNCIAS}

1. Gerlach RF, Souza ML, Cury JA. Esmalte dental com defeitos: de marcador biológico a implicações clínicas. Rev Odonto Ciência. 2000;15(31):87-102.

2. Assis GF, Ribeiro DA, Campos PD, Cestari TM, Taga R. Comparative stereologic study between secretory and maturation ameloblasts in rat incisors. J Appl Oral Sci. 2003;11(2):144-149.

http://dx.doi.org/10.1590/S1678-

\section{1}

3. Santos MLG, Line SRP. The genetics of amelogenesis imperfecta. J Appl Oral Sci. 2005;13(3):212-7.

http://dx.doi.org/10.1590/S1678$\underline{77572005000300002}$

4. Hoffmann RHS, Souza MLR, Cypriano S. Prevalência de defeitos de esmalte e sua relação com cárie dentária nas dentições decídua e permanente, Indaiatuba, São Paulo, Brasil. Cad Saúde Púplica.
2007;23(2):435-444.

http://dx.doi.org/10.1590/S0102-

$\underline{311 \times 2007000200020}$

5. Costa DP, Mota ACM, Bruno GB, Almeida MEL, Fonteles CSR. Desnutrição energético proteica. Rev Nutr Campinas. 2010;23(1):119126.

6. Li Y,Megan KP, Melissa AK, Li P, Bouchard J, Soon YH, Carolyn WG. Dental enamel structure is altered by expression of dominant negative rhoA in ameloblasts. Cells Tissues Organs. 2011;(194);227-231.

7. Seow WK, Fracs JPB, David I, O'Callaghan M. Developmental defects in primary dentition of low-birthweight infants: adverse effects of laryngoscopy and prolonged endotracheal intubation. Pediatr. D. Ent. 1984;6(1):28.

8. Coutinho TC; Portela W. Hipoplasia de esmalte: tratamento com facetas estéticas e coroas de aço. RGO. 1995;43(2):89-92.

9. Possobon RF, Carrascoza KC, Tomita ML, Ruiz JM, Scarpari CEO, Moraes ABA.Hipoplasia de esmalte em dentes decíduos. RFO. 2006;11(2):73-76.

10. Gomes FS. Defeitos de desenvolvimentos dentário em dentes decíduos [dissertação]. Porto: Universidade Fernando Pessoa; 2011.

11. Lunardelli SE, Peres MA. Prevalence and distribution of developmental enamel defects in primary dentition of pre-school children. Braz Oral Res. 2005;19(2):9-144. http://dx.doi.org/10.1590/S180683242005000200013

12. Pinheiro IFA, Medeiros MCS, Andrade AKM, Ruiz PA. Lesões brancas no esmalte dentário: Como diferenciá-las e tratá-las. Rev Bras Patol Oral. 2003;2(1):11-18. 
13. MC Donald RE, Avery DR. Odontopediatria. 7.ed. Rio de Janeiro: Guanabara koogan; 2000. p.76-108.

14. Pimlott JFL, Howley TP, Nikiforuk G, Fitzhardinge PM. Enamel defects in prematurely-born, low birth-weihgt infants. Pediatr Dent.1985;7(3):218-223.

15. Slayton RL, WarrenJJ, Kanellis MJ, Levy SM, Islam M. Prevalence of enamel hypoplasia and isolated opacities in the primary dentition. Pediatric Dentistry. 2001;23(1):32-36.

16. Franco $\mathrm{K}$, Line $\mathrm{S}$, Moura-Ribeiro $\mathrm{M}$. Prenatal and neonatal variables associated with enamel hypoplasia in decíduos teeth in low birth weight preterms infants. Journal of Applied Oral Science. 2007;15(6):518-523. http://dx.doi.org/10.1590/S1678-

\section{2}

17. Diniz MB, Coldebella CR, Zuanon ACC, Cordeiro RC. Alterações orais em crianças prematuras e de baixo peso ao nascer: a importância da relação entre pediatras e odontopediatras. Rev Paul Pediatr. 2011;29(3):449-55.

http://dx.doi.org/10.1590/s0103-

$\underline{05822011000300022}$

18. Machado AAC, Costa BR, Gomes LRG, Fragelli $C M B$. Prevalência e etiologia de defeitos de esmalte em dentes decíduos e permanentes. Rev Uningá. 2013;15(1):48-54.

19. Fiol FSD, Junqueira FM, Rocha MCP, Toledo MI, Filho SB. A febre Maculosa. Rev Panam Salud Publica. 2010;27(6):461-6. http://dx.doi.org/10.1590/S1020$\underline{49892010000600008}$

20. Canger EM, Celenk $P$, Yenísey $M$, Odyakmaz SZ. Amelogenesis imperfecta hypoplastic type associated with some dental abnormalities. Bras Dent J. 2010; 21(2):170$174 . \quad$ http://dx.doi.org/10.1590/S0103$\underline{64402010000200014}$

21. Moura LB, Blasco MAP, Costa VPP, Cruz MK, Lubian CT, Torriani DD. Avaliação clínica e radiográfica de dentes decíduos intruídos por traumatismo alvéolo-dentário. Pesq Bras Odontoped Clin Integr. 2011;11(4):601-6. http://dx.doi.org/10.4034/PBOCI.2011.114.2 $\underline{2}$

22. Takahashi K, Correia ASC, Cunha RF. Molar Incisor Hypomineralization. J Clin Ped Dentistry, 2009;33(3):193-198.

Recebido para publicação em 12/08/2014 Revisado em 03/09/2014

Aceito em 12/09/2014 